rev Psi

Revista de Psicología (UNLP)

https://revistas.unlp.edu.ar/revpsi

\title{
Autismo y psicoanálisis. Una apuesta del lado de la vida
}

\author{
Claudia Lijtinstens ${ }^{1,2}$ \\ Correspondencia \\ clijtinstens@gmail.com \\ Filiaciones institucionales \\ ${ }^{1}$ Escuela de la Orientación Lacaniana (EOL, \\ Argentina)
}

${ }^{2}$ Facultad de Psicología (Universidad Nacional de Córdoba, Argentina)

\section{Resumen}

Cuando la inscripción de la dimensión simbólica del lenguaje no se produce eficazmente el niño debe encontrar soluciones singulares para estructurar la realidad, su cuerpo y los objetos pulsionales que se despliegan entre la necesidad, la demanda y el deseo. El "tratamiento" que algunos niños realizan en relación a su cuerpo, a los objetos pulsionales y al Otro en ese intento de organización de su mundo -muchas veces extraño, paradojal, repetitivo e incomprensible-, dan cuerpo a la noción de autismo. La operación propia del psicoanálisis sobre la escritura del síntoma consiste en leer el modo en que cada sujeto elabora un pequeño circuito o cadena que instaura un montaje defensivo a la luz de una articulación entre cuerpo, objetos y lenguaje que se vuelve soporte de una acción no sometida a la interlocución simbólica ni dominada por la reciprocidad imaginaria, inventando junto al sujeto un modo de funcionar del lado de la vida y del deseo.

\section{Palabras clave}

autismo | psicoanálisis $\mid$ modo de funcionar $\mid$ deseo

\section{Proceso editorial}

Recibido

16 sep. 2020

Aceptado

1 jun. 2021

1 ra decisión

3 feb. 2021

Publicado

30 jul. 2021
Coordinadora del dossier

María Cristina Piro (Facultad de Psicología UNLP, Argentina).
ISSN

2422-572X

\section{Licencia}

Licencia de Cultura Libre CC-BY 4.0

(Compartir - Adaptar - Atribuir)

\section{Entidad editora}

RevPsi es una publicación de la

Facultad de Psicología (Universidad

Nacional de La Plata, Argentina) 


\section{Autismo e psicanálise. Uma aposta pelo lado da vida}

\section{Resumo}

Quando a inscrição da dimensão simbólica da linguagem não ocorre efetivamente, a criança deve encontrar soluções singulares para estruturar a realidade, seu corpo e os objetos dos impulsos que se desdobram entre necessidade, demanda e desejo. $\mathrm{O}$ "tratamento" que algumas crianças realizam em relação ao seu corpo, aos objetos de acionamento e ao Outro nesta tentativa de organizar seu mundo - muitas vezes estranho, paradoxal, repetitivo e incompreensível -, dá forma à noção de autismo. A operação da psicanálise sobre a escrita do sintoma consiste em ler a forma como cada sujeito elabora um pequeno circuito ou corrente que estabelece uma montagem defensiva à luz de uma articulação entre corpo, objetos e linguagem que se torna o suporte de uma ação não sujeita a interlocução simbólica nem dominada por uma reciprocidade imaginária, inventando junto com o sujeito uma forma de funcionamento do lado da vida e do lado do desejo.

\section{Palavras-chave}

autismo | psicanálise | modo de funcionamento | desejo

\section{Autism and psychoanalysis. A bet on life}

\section{Abstract}

When the inscription of the symbolic dimension of language does not occur effectively, the child must find unique solutions to structure reality, his body and the objects of drives that unfold between need, demand and desire. The "treatment" that some children undertake in relation to their body, to the objects of drive and to the Other in this attempt to organise their world - often strange, paradoxical, repetitive and incomprehensible - give shape to the notion of autism. The operation of psychoanalysis on the writing of the symptom consists in reading the way in which each subject elaborates a small circuit or chain that establishes a defensive montage in the light of an articulation between body, objects and language that becomes the support of an action not subjected to symbolic interlocution nor dominated by imaginary reciprocity, inventing together with the subject a way of functioning on the side of life and desire.

\section{Keywords}

autism | psychoanalysis | mode of functioning | desire 
Para que alguien pueda hablar y comunicarse, identificarse a sí mismo, reconocerse y reconocer a los otros -es decir, insertarse en un lazo social- hace falta que el lenguaje se inscriba no sólo como instrumento de comunicación sino en su dimensión simbólica, esa que ordena la subjetividad humana.

El lenguaje organiza la vida del ser-hablante; su inscripción permite reconocer las satisfacciones del propio cuerpo a partir de la dialéctica con los objetos pulsionales que se emplazan entre la necesidad (la indefensión) de ese cuerpo, la demanda del Otro y el deseo resultante de tal operación, estableciendo un lazo social.

Es lo que permite regular el mundo, reconocer un adentro y un afuera, inscribir las coordenadas espacio-temporales, adaptarse y acomodarse a las pautas, interpretar las demandas del medio y los fenómenos del entorno, inscribiendo el código de la comunicación sin que eso resulte ni invasivo ni amenazante.

Cuando esa inscripción -temprano en la infancia- no se produce de un modo eficaz el niño debe encontrar soluciones para enfrentar los efectos invasivos y devastadores del cuerpo y el lenguaje, originando una forma singular de estructurar y percibir la realidad. Esto es el autismo.

Estas soluciones que el niño autista construye no alcanzan a conformar un andamiaje subjetivo lo suficientemente dúctil y flexible. Por el contrario, lo que en general logra construir es una estructura más bien sellada y estrecha en la que prevalece una forma defensiva rígida con la que se protege de un entorno que no alcanza a interpretar y de un lenguaje que no logra decodificar.

Estos niños experimentan el jugar, el hablar, el aprender, como un riesgo de intrusión y forzamiento permanente por lo que tanto su cuerpo como los objetos se vuelven elementos esenciales de esa organización defensiva frente a aquello que los invade y que no puede ser significantizado.

Es eso lo que muestran algunos niños cuando se balancean, mueven sus manos de formas extrañas o toman algún objeto o una parte de este para manipularlo de una manera particular, o cuando construyen aprendizajes y "saberes" de maneras parciales y específicas.

Entonces, para acompañar a un niño que presenta estas características -y por supuesto también a sus familias- hace falta poder descifrar ese "tratamiento" que el niño ya viene realizando en relación a su cuerpo, a los objetos, al Otro, en ese intento de organización -muchas veces extraño, paradojal, repetitivo e incomprensible- de su mundo.

Y acompañar implica leer, en tanto operación propia del psicoanálisis sobre la escritura del síntoma entre el cuerpo y el lenguaje (Miller, 2011), el original modo en que cada sujeto elabora un pequeño circuito o cadena singular (Laurent, 2013, p. 84) que instaurara un montaje defensivo a la luz de una particular articulación entre cuerpo, objetos y lenguaje.

El modo singular en el que el cuerpo se presenta -desanudado del significante, sin 
bordes ni orificios-, instala esa desafección y ajenidad tan frecuentes en el autismo, haciendo emerger ese desorden de la pulsión que denominamos "la pulsión en lo real” (Miller, 2012, p. 110): un cuerpo que goza de sí mismo -el goce autoerótico por antonomasia-, que se entrega a una repetición que prolifera con sus propias normas. Es por ello que el tratamiento que realiza a partir de un objeto que, paradojalmente no ha sido extraído del campo del Otro, no ha sido cedido, consiste en sustraer su cuerpo de las palabras y del lazo para aislarse con ese objeto electivamente erotizado (Laurent, 1999, p. 88) que le permitirá construir un borde y circunscribir una pulsación significante ligada a una satisfacción.

Y para desplazar ese borde, para ampliarlo, para promover soluciones de mayor consentimiento al lazo social es preciso volverse "partenaire" de ese sujeto; soporte u operador de una acción que no quede sometida a la función de interlocución simbólica ni dominada por la reciprocidad imaginaria.

El aprendizaje de formas más o menos mecanizadas de habilidades sociales, el adiestramiento de los comportamientos atípicos desprecia, el enorme esfuerzo que hace ese sujeto para ordenar su mundo y de defenderse de lo intrusivo que este se pueden volver.

Lo cierto es que cada vez que se implementa -como estrategia de aproximación o de terapéutica- la "norma" como fin en sí misma, cuando se pone el acento en la adquisición de habilidades sociales arbitrarias, sólo se encuentra el rechazo y el repliegue del niño y, por supuesto, una mayor segregación.

El psicoanálisis, en cambio, aloja ese resto subjetivo original que no se deja someter a los intentos de educación o de adiestramiento; le atribuye un lugar y hace de ello el material para proponer al niño la invención de algo nuevo.

Elevar cada estrategia defensiva, cada artificio que el niño construye, a la "dignidad del significante", esto es, restituirle su valor de construcción singular que lo representa, es la delicada tarea a realizar; es lo que se requiere para poder acompañar -a ellos y a quienes están a su lado- a encontrar invenciones propias que faciliten su inscripción en la vida.

Estas invenciones propias son las que permitirán sobrellevar los avatares que provoca el encuentro con eso que no alcanza a ser significantizado, lo "no programable" del devenir.

Y estas invenciones deben, necesariamente, incluir esos "objetos", esas estereotipias, esos intereses específicos, como elementos privilegiados para tratar la realidad. El psicoanalista reconoce allí el esfuerzo de ese sujeto por encontrar alguna solución para permanecer entre otros.

El discurso del psicoanálisis advierte que existe en el ser hablante una fractura esencial que deja una huella singular, un traumatismo no eliminable y propone acompañar ese fallar, entre el cuerpo y el lenguaje -en las múltiples y sutiles maneras en las que se presenta- inventado, con eso mismo, un nuevo modo de hacer y de funcionar, del lado de la vida y del deseo. 


\section{Referencias}

Miller, J.-A. (2011). Leer un síntoma. AMP Blog. HTTPS://ELP.ORG.ES/LEER-UN-SINTOMA-JACQUES$\underline{\text { ALAIN/ }}$

Laurent, E. (2013). La batalla del autismo. Grama

Miller, J.-A. (2012). Embrollos del cuerpo. Paidós

Laurent, E. (1999). Hay un fin de análisis para los niños. Colección Diva. 